\title{
ANTIFAŠIZAM KAO MESTO SEĆANJA: ČITANJE IZ PERSPEKTIVE 21. VEKA
}

Ovaj tekst je motivisan sve prisutnijim pokušajima revizije istorije i relativizacije antifašističke borbe i njenog nasleđa. Imajući u vidu i politizaciju antifašastičkog mita $u$ NDR-u i SFRJ, rad je fokusiran na prozu pisanu nakon Drugog svetskog rata u SFRJ koja propituje upravo tu mitologizaciju, ali i sama konstituiše antifašizam i njegove vrednosti kao mesto sećanja i književni narativ. Uz sažet pregled najupečatljivijih književnih doprinosa na polju kritičkog promišljanja Drugog svetskog rata (Kocbek, Davičo, Bulatović, Kiš, Tišma), posebno su analizirani dramski tekstovi Slobodana Šnajdera, čiji se književni i intelektualni antifašistički angažman nastavlja i u postjugoslovenskom kontekstu. Šnajderova kultna drama Hrvatski Faust (1981) se preko intertekstualnih referenci i postupka „drame u drami““ bavi odnosom umetnosti, slobode i njenih granica u kontekstu državne i političke represije i zločina. Dramom Peto evanđelje (2004) se antifašizam kao mesto sećanja oblikuje kroz, u velikoj meri tabuiziranu temu koncentracionog logora.

Ključne reči: antifašizam, mesto sećanja, narativi sećanja, jugoslovenske književnosti, Hrvatski Faust

„Ne postoji zajednička kultura sećanja“, primedba je scenariste Štefana Koldica (Stefan Kolditz), odraslog u NDR-u, jedinog istočnonemačkog člana tima okupljenog oko nove dramatizacije romana Nag među vukovima Bruna Apica (Nackt unter Wölfen, Bruno Apitz, up. Leo, 2015: 3). Ova knjiga je u NDR-u bila deo kanona antifašističkog identiteta, a samim tim i školske lektire. Presudno je uticala na naše shvatanje antifašističkog otpora u mladim godinama ${ }^{1}$. Po Koldicovim rečima, međutim, na Istoku je antifašizam korišćen kao utemeljiteljski mit, a na Zapadu je antikomunizam ponekad bio izraženiji od gnušanja prema nacistima. Izgleda da su obe nemačke države koncipirale sećanje i zaborav kakvi su im bili potrebni za budućnost.

\footnotetext{
*angela.richter@slavistik.uni-halle.de

${ }^{1}$ Novo izdanje romana u berlinskoj izdavačkoj kući Aufbau-Verlag (2012) sadrži odlomke koji su u prvom izdanju iz 1958. „modifikovani“ da bi odgovorili mitu o samooslobođenju konclogora i o vodećoj ulozi komunista u pokretu otpora.
} 
Novinski članak, u kojem se citiraju sećanja udovice pisca Štefana Koldica na nastanak romana, opet podseća na to da se mišljenja po pitanju ocene antifašizma razilaze, što se da videti i po diskusijama u zadnje dve decenije, i to ne samo u Nemačkoj. Zadnjih godina se mnogo govorilo i pisalo o ambivalentnosti antifašizma kao utemeljiteljskog mita NDR-a, kao i uopšte o antifašizmu na Istoku i Zapadu (up. Leo, Reif-Spirek, 1999 i 2001; Ahbe, 2007; Münkler, 2009; Sabrow, 2009). Pri tome je postalo jasno da su NDR-ov diskurs zasnovan na kritici kapitalizma i nastojanja da se legitimizuje njegova ideološka supremacija nad Zapadnom Nemačkom, kao i politika konfrontacije između dve Nemačke zamaglili pogled na mnoge aspekte nacionalsocijalizma i Trećeg Rajha.

Mišljenja sam, pak, da se pojam antifašizma u odnosu na NDR ne može razumeti samo kao komunistička parola ili sinonim za državnu i režimsku politiku sećanja, nego podrazumeva i aktivno suprotstavljanje fašizmu i nacionalsocijalizmu, jedan sveopšti angažman i jednu opciju u korist humanosti i pravde (up. i Leo, 2009: 28-40). U ovom tekstu pod antifašizmom podrazumevam pokret sa različitim, pa i suprotstavljenim obrascima mišljenja i delovanja, sa građanskom hrabrošću u korist otpora fašističkom režimu do 1945. godine, nacionalsocijalizmu i ideologiji krvi i tla.

Što se tiče jugoslovenskog konteksta, kojem je posvećena ova studija, antifašizam je bio temeljni narativ jugoslovenskog socijalizma, kako između ostalih ističe beogradski sociolog Todor Kuljić. Bio je

u izvesnoj meri vrhunac svih oslobodilačkih ratova i glavni sadržaj komunističke kulture sećanja zasnovane na toposu oslobođenja. On se oslanjao na izrazito dualističku predstavu rata, kojom se uspostavljala statična suprotnost između pozitivnih i negativnih junaka, između žrtava i počinilaca, između dobra i zla. (Kuljić, 2010: 122).

Raspadom SFRJ (kao i ukidanjem NDR-a) antifašizam se izlizao kao državna doktrina, čime je uzdrmana kanonska antifašistička kultura sećanja. Ipak, po mom mišljenju, antifašizam ostaje neupitan kao transnacionalno mesto sećanja na otpor fašizmu sa strane „,bezrazlikovne ideologije sledbeništva“ (Danyel, 1995: 42) i sa strane politike moći. Ili bi se barem trebalo podrazumevati da je u Evropi postignuta dovoljna saglasnost po tom pitanju. Dovoljna, zato što je antifašizam kao glavni oslonac legitimacije postao prva žrtva „terora zaborava“, kada su, na primer, nacionalističke elite u Jugoslaviji saveznu državu i socijalistički model društva proglasili zabludom i demontirali Jugoslaviju, kao što Dubravka Ugrešić s gorčinom navodi u svojoj knjizi Kultura laži (Ugrešić, 1994: 120). 
„Anti-antifašizam je postao izazov za antifašizam, tako važan za socijalističku Jugoslaviju, anti-antifašizam, koji u 'najboljem' slučaju trpa komunizam i fašizam u isti koš ('totalitarizma'), a u najgorem nastoji da spere ljagu sa domaćeg fašizma", piše istoričar Ulf Brunbauer u predgovoru knjizi Todora Kuljića Umkämpfte Vergangenheiten. Die Kultur der Erinnerung im postjugoslawischen Raum (Bitka za prošlost. Kultura sećanja u postjugoslovenskom prostoru), u kojoj se novi poredak kulture sećanja u državama nastalim raspadom Jugoslavije podvrgava kritici (Brunnbauer, 2010: 9).

Tijekom proteklih dvadesetak godina, Hrvatska je (kao i druge države bivše Jugoslavije) bila podijeljena oko Drugog svjetskog rata, što je uključivalo rehabilitaciju počinitelja fašističkih zločina, dok je sjećanje na žrtve fašizma sistematski izbrisano. Sjećanje na traumatsku prošlost formira se kroz komemorativne događaje, spomenike, usmenu povijest i osobna sjećanja, povijesne knjige i, naravno, politički diskurs. Međutim, sjećanje se također rekreira i reinterpretira kroz kulturne proizvode i umjetnost, kao npr. dramske predstave, romane i filmove. Neki režimi koriste film u svrhu legitimacije svojih političkih sistema, dok demokratske države koriste film u svrhu rasprave i bavljenja teškim trenucima povijesti,

pisalo je u proleće 2015. godine povodom tribine na temu „Antifašizam između povijesti i pamćenja“ $u$ art bioskopu „Croatia“ u Rijeci (up. Tribina). Vreme je, dakle, da se u tom smislu pozabavimo temom antifašizma kao mesta sećanja, odnosno antifašističkim narativom sećanja i u takvim umetničkim tekstovima koji su nastali posle 1945. godine na temu Drugog svetskog rata, antifašističkog otpora, tj. antifašističke oslobodilačke borbe i socijalističke revolucije. Ovaj pojmovni konstrukt povezuje oslobodilačku borbu i socijalno oslobođenje, nacionalnu i socijalnu obnovu i postaje osnovna didaktička i istoriografska kategorija u predstavljanju rata (up. Höpken, 1996: 169). Da se ukratko podsetimo: Federativna, a kasnije Socijalistička Federativna Republika Jugoslavija nastala je 1945. godine nakon Drugog svetskog rata koji je odneo brojne živote. Rat nije bio samo oslobodilački rat protiv fašističkih okupatora razne provenijencije, već i građanski rat. Nadnacionalni i multietnički partizanski pokret, sastavljen ne samo od komunista, raspolagao je najkasnije nakon Drugog zasedanja AVNOJ-a krajem novembra 1943. godine ideološkim i političkim konceptom u kome su se raspoznavali obrisi budućeg socijalističkog društvenog ustrojstva. Partizani su postali nešto kao ,supraetnički simbol svih nacija“ (Jambrešić-Kirin, 2006: 166, podvučeno $\mathrm{u}$ originalu). Generalizacija je postignuta nadnacionalnim načelom 'bratstva i jedinstva'. Istaknuti poznavalac istorije Jugoslavije, pok. prof. Holm Sundhaussen je situaciju opisao ovako:

1. Kada je Drugi svetski rat u aprilu 1941. godine napadom 'sila osovine' dospeo i do Jugoslavije, niko nije mogao ni da pretpostavi da će ona na kraju rata postati 
komunistička zemlja. Jugoslavija je bila jedina socijalistička država u Evropi, koja je provela izmenu društvenog sistema tokom Drugog svetskog rata i kao posledicu rata, i to isključivo sopstvenim snagama, izuzimajući kratku saradnju sa Crvenom armijom u jesen 1944. godine prilikom oslobođenja Beograda i Vojvodine. Jugoslovenski 'poseban put' počeo je dakle ne tek uspostavljanjem jednog nadasve samosvojnog modela socijalizma između 1950. i 1976. godine, nego već tokom rata. 2. Svetski rat na tlu Jugoslavije bio je višeslojan: rat između okupatora $i$ pokreta otpora, ideološki rat između komunista i antikomunista, između 'fašista' i 'antifašista' i konačno - etnički rat. [...] 3. Istorija rata od 1941. do 1945. godine postala je središte posleratne istorije i tek od pre nekoliko godina potisnuta je u drugi plan istorijom ratova 90-ih godina“" (Sundhaussen, 2012: 49).

Do 80-ih godina zvanično sećanje na rat nije bilo sećanje na kolaboraciju i komunističku odmazdu. Pomenuti, usko isprepleteni aksiomi antifašističke memorije poljuljani su u zvaničnoj kulturi sećanja jugoslovenske socijalističke države posebno nakon smrti doživotnog predsednika Josipa Broza Tita 1980. godine. Sve u svemu, treba reći da diskusije o kulturama sećanja u novonastalim nacionalnim državama ne prestaju sve do danas, ${ }^{2}$ i svakako se ne može govoriti o saglasnosti u pogledu prošlosti. „Nakon raspada Jugoslavije granica između fašizma i antifašizma izgubila je na značaju: antifašizam je obezvređen, a uticajni intelektualci i jedan deo istoričara sve češće su ga proglašavali pokretom kontaminiranim komunizmom“ (Vegel, 2008: 30).

Po skorašnjim uvidima istoričara Aleksandra Jakira ,the official version of the memory of World War II in socialist Yugoslavia did not reflect plurality, nor did it attempt to integrate dissenting views. It promoted the memories that endorsed the regime and its ideology, and repressed other narratives" (Jakir, 2012: 193). To je načelno tačno u pogledu na društveno-strateške odluke socijalističke vlasti. Ali, kako je u vezi sa sećanjem na mrtve i na podizanje spomenika pokazala istoričarka Hajke Karge (Heike Karge), na lokalnom nivou se ne realizuje nužno „državno podržana ratna naracija“, već je stanovništvo u stanju da ,preoblikuje elemente zvanične ratne naracije primenom lokalno, kulturno ili istorijski zasnovanih tehnika sećanja“ (Karge, 2006: 93; Karge, 2010). Da li navedena izjava načelno važi i za umetnost? Kao što su pokazali najnoviji radovi, moramo daleko pažljivije posmatrati i utvrđivati razlike $u$ interpretacijama prošlosti, znajući da je i liberalnost u socijalističkoj Jugoslaviji imala svoje granice

\footnotetext{
${ }^{2}$ Zanimljivi uvidi u tradiranje istorijske svesti u porodičnim pričama iz Srbije i Hrvatske i o interesu za Drugi svetski rat pružila je Natalija Bašic (Bašić, 2007). Liljana Radonić je objavila obimnu studiju o politici prošlosti u Hrvatskoj (Radonić, 2010).
} 
(Richter, 1995; Peković, 2009). Do granica slobode umetničkog izražavanja bi se dolazilo čim bi bili dovedeni u pitanje partizanski mit, mit o Titu i/ili socijalističko samoupravljanje, odnosno ako su umetnička dela u celini mogla biti okarakterisana kao 'antisocijalistička'.

\section{DA LI JE U POGLEDU ANTIFAŠIZMA VLADALA OPŠTA SAGLASNOST}

\section{U KNJIŽEVNOSTI?}

Postoji mnoštvo književnih tekstova (kao i filmova i pozorišnih komada) o Drugom svetskom ratu, antifašističkom pokretu otpora, odnosno o jugoslovenskoj 'narodnooslobodilačkoj borbi'. Negde do sredine 60-ih godina taj je narativ u svakom slučaju bio karakterističan za jugoslovenske književnosti. U ideološkim i moralnim sukobima posleratnog vremena takvi tekstovi su prihvatani manje-više kao 'dokumentarni primer' kojim se nastojalo postići razumevanje za socijalne prevrate, odnosno za njihovu idejnu afirmaciju. Kao takvi ubrzo su ušli u zvanični književni kanon SFRJ. Brojni romani te vrste sa centralnim toposom antifašističkog narodnog oslobođenja uticali su $\mathrm{u}$ bitnoj meri i na recepciju jugoslovenskih književnosti u NDR-u, zemlji koja se zasnivala na tradiciji antifašizma i u kojoj se nastojalo da se takav pristup prilagodi kulturnopolitičkom konceptu. Mora se, međutim, naglasiti da su se već vrlo rano i bez obzira na interpretativne okvire državne politike sećanja u Jugoslaviji pripovedale i „druge priče“ (Colombi, 2014) i da su malo-pomalo doprinosile stvaranju alternativnog diskursa o Drugom svetskom ratu i antifašizmu, a danas se insistira na tome da se te priče na dostojan način vrednuju i uključe u ukupnu istoriju razvoja, afirmacije i dekonstrukcije narativa sećanja u politici/politikama sećanja.

Zbirka novela Strah in pogum (1951; Strah i hrabrost) slovenačkog autora Edvarda Kocbeka (1904-1981), koji je prikazao specifičan doživljaj partizanskog života i na empatičan način predstavio unutrašnje konflikte $\mathrm{i}$ traume pojedinaca $u$ graničnim situacijama, kada su imali zadatak da 'u ime istorije' odlučuju o životu i smrti drugih (up. Bernik-Dolgan, 1988; Richter, 1995; Colombi 2014). Takođe, treba pomenuti obimni ,antifašistički urbani roman“ (up. Kenneweg, 2009: posebno 117-136) Pesma srpskog nadrealiste Oskara Daviča, čiji je - za razliku od drugih romana odgovarajuće tematike - gradski milje, u kome se odvija radnja, uz odgovarajući ansambl likova imao zadatak da otvori mogućnost drugačijih interpretacija antifašističkog delovanja i razmišljanja njegovih aktera.

Roman Heroj na magarcu Miodraga Bulatovića (1930-1991) (objavljen prvo na nemačkom 1965. godine, a u originalu tek 1967. godine), posvećen Kurciju 
Malaparteu, predstavlja više od „neželjenog iskustva““3. Ovaj roman je potkopavanjem lika jugoslovenskog partizana kao dominantne figure sećanja zaobišao dotada uobičajeno upućivanje na rat i antifašizam i doveo u pitanje jedan od najvažnijih posleratnih mitova. Groteskni lik crnogorskog krčmara Grubana Malića, koji bi se rado angažovao za partizane, ali ga niko ne shvata ozbiljno, sa njegovom sklonošću ordenju, neobuzdanim osećanjima i trivijalnom željom za životom, sa orlovskim nosem i moćnim falusom, sa svojom ekspresivnom i delimično opscenom telesnošću i kratkom pameću postao je parodija crnogorskih herojskih ratnih likova. Bulatović prikazuje rat kao orgijastičko, izopačeno slavlje (Richter, 1999) i formuliše svoju nelagodu u odnosu na ratne mitove i priče o slavi ${ }^{4}$ kao književnu provokaciju. Bulatovića u svakom slučaju treba uzeti u obzir u budućoj istoriji lociranja antifašizma kao mesta sećanja u književnim tekstovima posle 1945. godine.

U kasnijim decenijama su postojeći književni narativi sećanja obogaćeni, subverzivno dekonstruisani integracijom novih aspekata $i$ to uprkos interpretativnom okviru zadatom 'narodnooslobodilačkom borbom' i partizanskim mitom. U javni život su nadirali alternativni interpretativni obrasci, odnosno dovođena je u pitanje opšta saglasnost u pogledu antifašizma. To je bilo povezano sa pojavljivanjem novih aktera na jugoslovenskoj kulturnoj sceni i sa pitanjem kako će oni definisati svoje mesto u jugoslovenskom društvu. Kao izuzetan primer treba navesti Danila Kiša (1935-1989), o kome postoji obimna literatura na međunarodnoj naučnoj sceni. On je - sa strane povlašćenog partizanskog narativa upozorio na suočavanje sa misterioznim i tragičnim nestankom ljudi u dvadesetom veku, što je i sam video kao srž svoje književnosti. Pokušaj 'rekonstrukcije' jevrejske Srednje Evrope i detinjstva čini trilogiju Bašta, pepeo (1968), Rani jadi (1969) i Peščanik (1972) izvanrednim doprinosom „post-Auschwitz-poetics“ (Vladiv-Glover, 1994). Kiš je decidirano izabrao perspektivu nemoćne žrtve. Autobiografskom motivacijom Kiš je preneo svoje suočavanje sa masovnim uništenjem Jevreja na porodični nivo, inscenirajući propast čitavog jednog sveta bez

\footnotetext{
${ }^{3}$ Tako glasi naslov knjige o ratnoj književnosti i cenzuri u NDR-u. Knjiga je 1989. nastala pod rukovdstvom germanistkinje Ursule Heukenkamp (up. Heukenkamp, 1990).

4 Bulatović je u razgovoru sa Bienekom bez mnogo ustručavanja izjavio: „Pisao sam prilično antimitološku knjigu, ali ipak objektivnu. Antimitološka je u svakom pogledu, i to se nikako ne odnosi isključivo na Jugoslovene. Savremena literatura - u Evropi i svugde prepuna je teških falsifikovanja. Ja sam hteo dati svoj skromni doprinos u kontekstu rada mnogih iskrenih pisaca koji se bore protiv svih tih dobro plaćenih mistifikatora [...]“ (up. Bienek, 1965: 19).
} 
patetike i baš zato sa ne manje upečatljivosti. Kiš je ispunio zjapeću prazninu. Svojim knjigama je na dnevni red stavio Holokaust sa kojim je bilo poteškoća u jugoslovenskoj politici sećanja. Ta perspektiva je bila pre svega kosmopolitska i nije imala puno veze sa elitama proizašlim iz partizanskog herojstva. Detaljnija analiza u okviru ove studije nije moguća usled pomanjkanja prostora, ali ipak treba naglasiti da progon Jevreja Kiš nije prikazao ni u klišeima niti bezazleno. „Delotvornost njegovih tekstova nalazi se u sažetosti i enciklopedijskoj jezgrovitosti rečenog, pri čemu istorijske veze treba iščitavati između redova. 'Hladni dani ${ }^{5}$ su samo jedan delić zločina nad Jevrejima, čiji tragovi se pronalaze u Kišovim delima“" (Petzer, 1998: 118).

U ovom kratkom i sažetom pregledu mora biti pomenut i Vojvođanin Aleksandar Tišma (1924-2003). Njegovim tekstovima, suštinski antifašističkog karaktera, imanentna je polemika protiv univerzalističkog prisvajanja tema kao što su Drugi svetski rat i Holokaust. Svojim romanima Knjiga o Blamu (1972), Upotreba čoveka (1975) i Kapo (1987) Tišma zadire, na mnogim nivoima, u kontekst kulture sećanja u Jugoslaviji 70-ih i 80-ih godina, prednjačeći pred jugoslovenskom istoriografijom. Već njegovi književni likovi reprezentuju tabuizirane aspekte rata, otpora i stvarnosti logora: Jevrejin Blam slučajno preživi i oseća se krivim jer nije ispunio predodređenu mu sudbinu; jevrejski kapo je preživeo, zato što je - koristeći lažni identitet - menjao stranu i postao ugnjetač; polujevrejki Veri Kroner je logorska prostitucija upisana u telo, čime je njena trauma postala neprevladiva; mladog Sredoja Lazukića groteskna slučajnost vodi u partizane. Spisak takvih i sličnih primera je dug.

Dok Tišma na početku nije bio prevođen ni u Istočnoj ni u Zapadnoj Nemačkoj, to se počev od 90-ih godina u Nemačkoj bez njega ne može zamisliti polemika o sećanju na Drugi svetski rat i Holokaust, o memorijalizaciji i problematici odnosa zločinca i žrtve. ${ }^{6}$

\footnotetext{
${ }^{5}$ Tako se eufemistički označava masakr (logičnije bi bio plural, jer ih je bilo više) početkom 1942. u Novom Sadu i drugim mestima u Vojvodini koji su mađarski fašisti počinili nad Jevrejima, Srbima i Romima. Medijski izuzetno praćen proces protiv jednog od glavnih počinilaca koji je 2011. počeo u Budimpešti, završio se njegovim oslobađanjem od optužbe.

${ }^{6} \mathrm{U}$ članku koji se posebno bavio recepcijom Aleksandra Tišme na nemačkom govornom području, konstatovano je da u novije vreme nema ni jednog autora iz Jugoslavije koji je više praćen književnom kritikom od A. Tišme (up. Richter, 2006).
} 
KONTROVERZAN ODNOS PREMA ZVANIČNOJ KULTURI SEĆANJA U JUGOSLOVENSKOM SOCIJALIZMU - SLOBODAN ŠNAJDER

Za antifašizam kao mesto sećanja u umetnosti od posebne su važnosti likovi partizana i partizanska sećanja. U ovom kontekstu se konačno može posegnuti za građom iz koje se upečatljivo može pojmiti ,interakcija sveobuhvatnog narativa i kontradiskursa, odnosno zvaničnih i alternativnih narativa“ (Colombi, 2014: 175). To ga čini i posebno privlačnim za istraživačke poduhvate (up. od novijih radova Jakiša, 2012; Colombi, 2014; Jakiša-Gilic, 2015). Osim toga lik partizana 'ponovo ulazi u modu' u postjugoslovenskim državama.

Međutim, ovde bih izabrala jedan drugačiji fokus za pojašnjenje problematike sećanja i antifašističkog nasleđa. Detaljnijom analizom dramskih dela Slobodana Šnajdera osvetliće se rad autora koji se nije angažovao u polju politike sećanja samo u socijalističkoj Jugoslaviji, već i nakon njenog raspada. ${ }^{7} \mathrm{Za}$ temu ovog rada je paradigmatična njegova drama Hrvatski Faust (1981, praizvedba 1982. u Splitu). ${ }^{8}$

U vreme nastanka ove drame državna politika sećanja je još uvek izrazito orijentisana na Drugi svetski rat i 'narodnooslobodilačku borbu'. Doduše, 'Hrvatsko proljeće’ 1970/71. godine već pokazuje stremljenja u pravcu daljeg osamostaljenja Hrvatske (Sundhaussen, 2013: 42). Opet uskrsava nacionalno pitanje. Zavisnost Komunističke partije od „legitimacijske supstance prikaza rata“ (Höpken, 1996: 164) radi obezbeđenja monopola vlasti nije otvarala prostor za otvorene diskusije o ambivalentnosti istorije i višeslojnosti iskustava. U tom kontekstu Šnajder poseže za autentičnim događajem, naime za predstavom Fausta 31. marta 1942. godine u Hrvatskom narodnom kazalištu (HNK), kojoj je prisustvovala čitava politička elita hrvatske fašističke države (NDH). Izvedbom se svečano slavila simbolična povezanost hrvatskog naroda sa germanskim duhom, zahvalnost 'oslobodiocima' i

\footnotetext{
${ }^{7}$ Povodom jedne konferencije 2007. u Trieru sam govorila o Šnajderovoj suptilnoj polemici o nekim segmentima koji nedostaju u već postojećim slikama istorije i politikama sećanja. Ovde uključujem deo tog materijala.

${ }^{8}$ Praizvedba je bila na festivalu Splitsko ljeto u HNK Split, 7. kolovoza 1982.; reditelj: Slobodan Unkovski. Sledila su: Narodno kazalište „August Cesarec“ Varaždin, 1982., reditelj: Petar Vecek; Jugoslovensko dramsko pozorište Beograd, 1982., reditelj: Slobodan Unkovski; Narodno pozorište Sarajevo, 1983, reditelj: Sulejman Kupusović; Theater an der Ruhr, Mülheim, 1987, reditelj: Roberto Ciulli; Wiener Burgtheater, 1993, reditelj: Hans Hollmann.
} 
jedinstvo NDH sa hitlerovskom Nemačkom, i to baš preko figure Fausta reinterpretirane od strane ideologa nacionalsocijalizma u herojsku veličinu. ${ }^{9}$

Tri prologa nas uvode u tadašnje okolnosti. U prvom prologu se otkrivaju već od samog početka različite pozicije obojice budućih glumaca Fausta - Afrića i Žanka. Drugi prolog upućuje na atmosferu tokom proglašenja Nezavisne Države Hrvatske. Treći prolog se bavi preduzimanjem prvih mera poput Zakona o osnivanju Hrvatskog ureda za jezik i najavom prisilne prodaje nehrvatskih trgovinskih i zanatskih preduzeća. Prvi deo drame se završava svečanošću povodom premijere i begom glumca koji je igrao Fausta, a drugi deo je posvećen ponovnim priređivanjem komada s drugim glumcima i igrom do pada režima 1945. godine i dolaska predstavnika nove vlasti.

Pogled na ključne protagoniste omogućava približavanje osnovnim postavkama komada. Hrvatska kulturna scena je bila, i još uvek je iritirana činjenicom da se u komadu pojavljuju i likovi koji upućuju na stvarne istorijske osobe. Tu spadaju Vjekoslav Afrić, ${ }^{10}$ koji glumi Fausta i nakon premijere odlazi u partizane, zatim Janko Rakuša, drugi glumac Mefista, koga kao komunistu ustaše ubijaju 1945. godine, pisac i intendant Dušan Žanko, koji nakon Afrićevog odlaska u partizane preuzima ulogu U-Fausta, dakle preuzima fašističku ideologiju i na kraju Tito Strozzi, poznati reditelj, dramatičar i glumac. ${ }^{11}$ Dakle, u komadu se kritički postavlja i pitanje o ulozi nekih hrvatskih intelektualaca u kulturnoj infrastrukturi NDH (up. Bobinac, 2005: 143).

Tokom radnje se pokazuje da se odluka genijalnog glumca Afrića, kao apolitičnog bonvivana, da pređe na oslobođenu teritoriju i pridruži se partizanima, ne zasniva na čvrstim ideološkim stavovima i idealima kojima teži, već više na odlučnom protestu umetnika, čiji su položaj i umetničke slobode ugroženi rigidnom i nesnošljivom praksom režima i koji je izgubio veru u instituciju pozorišta: „Muka mi je od kazališta. Muka mi je od Fausta“ (Šnajder, 2007/9: 31). Proslava premijere protiče bez pompe i oduševljenja, proslavljeni glavni glumac više i nije među zvanicama. Ovde se završava prvi deo drame, koji se podudara sa antifašističkim konceptom sećanja. Hrvatski kolega Svjetlan Lacko Vidulić primećuje

\footnotetext{
${ }^{9}$ O tome se može čitati takođe kod Zorana Konstantinovića (1987), koji se u okviru tematskog kompleksa Faust - sotona, razmatrajući „diskurzivnost zla“ pozicionira prema Šnajderovom dramskom tekstu.

${ }^{10}$ Afrić je reditelj filma Slavica, prvog igranog filma posle Drugog svetskog rata (1947).

${ }^{11}$ Detaljnija objašnjenja autor daje u kratkom tekstu „Tko ovdje govori?“ (up. Šnajder, 2007/9: 13-17).
} 
„subverzivno, antifašističko-antititansko tumačenje Fausta. U etičkom smislu raspolućeni (glumac) Faust(a) sve se više distancira od nametnute nacionalističke 'transcendencije' hrvatske države uskrsle u večnu slavu i uz pomoć (glumaca) Mefista i Margarete priključuje se humanijem 'paklu' oslobodilačke borbe“" (Vidulić, 2011: 3).

U drugom delu prikazivanje pozorišnog komada se nastavlja, igra se sve do pada režima. Mefisto i Margareta, koji su Faustu pomogli da pobegne, igraju i dalje u komadu i uspešno se protive novom U-Faustu, fanatičnom direktoru pozorišta. Margaretu, koja nosi Faustovo/Afrićevo dete, muče tokom scene u bašti, a kasnije i ubijaju. Njenu ulogu preuzima devojka u ustaškoj uniformi verna načelima nove državne politike, a uloga Mefista poverava se poglavniku, odnosno narodu.

Intendant Žanko, koji hoće da napreduje u karijeri i pod promenjenim okolnostima, pojavljuje se javno u novoj uniformi i pokazuje time da fanatično veruje u uzvišenost novog ideološkog projekta. U komadu se paralelno sa zamenom glumaca iznose faktografski izveštaji sa fronta i izveštaji o masovnim egzekucijama u koncentracionom logoru Jasenovac. U jednoj od ključnih scena u zagrebačkoj katedrali, u razgovoru između Žanka i monsinjora Župetića, koji se upravo vratio iz inspekcije logora, dopušta se Žanku kratak šok kada vidi da je suvenir koji je dobio napravljen od ljudskih kostiju. Njegov zaključak je drugačiji nego što bi se očekivalo - spasavanje Hrvatske od 'boljševizma' mu je dovoljno opravdanje da ostane dosledan u svom fanatizmu. Taj nacistički Faust oplodi U-Margaretu i tako stvaraju veštačkog čoveka, homunkulusa u liku kepeca u zelenom čohanom mantilu i sa hitlerovskom frizurom - hrvatskog dobrog duha.

Skiciraju se i kratki prikazi drugih protagonista, kao na primer sluge Lipovšćaka, iz čijeg je nastupa jasno kakvog karaktera su ljudi koje fašistički sistem može brzo iskoristiti u svoje svrhe. Nadalje tu nastupa i stari Jambrek, ${ }^{12}$ koji sebi uzima za pravo da se u sceni provere etničke pripadnosti članova pozorišnog ansambla ponaša sa švejkovskom naivnošću i prostodušnošću, ismevajući predstavnike fašističke vlasti u jednom krajnje ozbiljnom trenutku.

Finale komada se kritički odnosi i prema budućem društvenom projektu. Faust/Afrić se vraća iz rata u pratnji partizanskog komesara, 'istorijskog pobednika'. Kad sazna za stvarne okolnosti smrti svoje žene i sina, od njega se uprkos svoje boli zahteva nepokolebljivost. Neumorni komesar kraj njega ne trpi žalost: „Budi vojnik, oficiru! Narod se ugleda na partizanske oficire! A oči naroda

12 Ovde se uspostavlja intertekstualna veza sa čuvenom zbirkom novela Hrvatski bog Mars (1923) Miroslava Krleže, u kojoj je razobličena militaristička ratna mašinerija Prvog svetskog rata. Domobran Jambrek je naslovna figura jednog od tekstova. 
su širom otvorene. Vama oficirima ništa se ne prašta“ (Šnajder, 2007/9: 102). Nametljivo objašnjava svoj lični spisak zadataka: „Kao prvo ću organizirati socijalizam. A onda i komunizam. Točno po voznom redu. To je organizacija plus elektrifikacija. Ići ću tamo gdje sam potreban [...]“ (op.cit. 243).

Šnajder protivreči toj viziji, odnosno savršenoj projekciji, naglašavajući prepoznatljive i upozoravajuće pojedinosti upućene čitaocu ili gledaocu (komesar nosi kožni mantil i oficirsku torbu preko ramena, iz daljine se čuju udarničke pesme, u kojima se slave Staljin, Sovjetski Savez, majčica Rusija, kao i pesme posvećene Titu). Komesar daje uputstva Afriću u vezi sa repertoarom i uopšte sa pozorištem, i odmah biva jasno da se funkcija pozorišta kao i estetska očekivanja neće mnogo razlikovati od smernica upravo srušenog nacionalističkog i fašističkog režima, čime se ponavlja ideološka manipulacija pozorišnom umetnošću, ali sada pod uslovima socijalističke revolucije. Od Fausta/Afrića se zahteva da se igraju klasični komadi (takođe i Faust) i sovjetske jednočinke, što ironično upućuje na kulturnu politiku novog režima, koji sa svoje strane teži osobenom kulturnom profilu. Već ranije zloupotrebljeni Faust će dakle preživeti. Šnajder pokazuje da se Adornova nada da su značajni tekstovi imuni na zloupotrebu nije ostvarila.

Umorno, ostarelo i rezignirano troglavo biće Faust-Margareta-Mefisto $\mathrm{u}$ epilogu ipak pozdravlja to „mladalačko ludilo“ (op.cit. 108), pa vizija budućeg boljeg sveta ipak ostaje maglovita, prekrivena snegom.

Slobodan Šnajder modifikuje elemente postojeće kulture sećanja. Protivi se jednostranom predstavljanju i favorizovanju određenih aspekata $u$ okviru antifašističkog narativa, koji treba da povezuje jugoslovenske narode i krši tabue na više načina - on demaskira nacionalsocijalistički period hrvatske istorije između 1941-1945. godine, neuvijeno prikazuje zločine u koncentracionom logoru Jasenovac, oko koga se sve do današnjeg dana vodi neumoljivi interpretacijski rat, propituje ulogu intelektualaca pri nastanku ekstremnog hrvatskog nacionalizma između dva rata kao i pri uspostavljanju i održavanju fašističke ustaške države za vreme Drugog svetskog rata. Šnajder je sve te aspekte izneo na scenu sa dotada neviđenom otvorenošću (up. Bobinac, 2005: 142). No, tadašnja javnost nije bila spremna da započne raspravu o složenim pitanjima bliske prošlosti koja se postavljaju u komadu, a nacionalizacija diskursa sećanja, koja se sa izvesnom žestinom nagoveštavala već krajem osamdesetih i koja doživljava svoj vrhunac devedesetih godina pod hrvatskim predsednikom Franjom Tuđmanom pružala je još manje mogućnosti za tako nešto. Radikalnost karakteristična za autora, pogotovo u pogledu fašizma $\mathrm{i}$ istorijskog revizionizma, u pogledu nasilja nad pojedincem $\mathrm{u}$ ime neke više instance, bez obzira da li se pri tome radi o domovini, naciji ili socijalnom sloju, vodila je ka tome da je on bio oklevetan kao izdajnik svog naroda i isključen 
iz književnog i pozorišnog života u Hrvatskoj. ${ }^{13}$ „Reaktualizovani kolektivni inventar sjećanja sa ogromnim emotivnim potencijalom“ (Vidulić, 2011: 6) pretvorio se sada u sukob interpretacija unutar Hrvatske.

$\mathrm{Ni}$ u toj tada tako teškoj situaciji autor nije odustao. Dramom Peto evanđelje (2004) ${ }^{14}$ Slobodan Šnajder se vraća problematici ustaštva i svakodnevici logora kao ključnim komponentama ostvarenja totalitarne ideologije.

Iako nema direktnog referiranja na ovo autobiografsko svedočanstvo, ključni značaj za Šnajderov dramski tekst imaju dnevnički zapisi hrvatskog pisca i publiciste Ilije Jakovljevića (1898-1948) Konclogor na Savi, rekonstruisani i objavljeni tek 1999. godine. Ilija Jakovljević je od 1941. do 1942. godine bio zatočenik logora Stara Gradiška, koji je bio jedan od logora u sistemu koncentracionog logora Jasenovac. Podsećajući na elemente revizionizma u kulturi sećanja pod Tuđmanovom vlašću devedesetih godina, kada su se mogle uočiti tendencije prevrednovanja ustaštva, NDH i logora, kao i promene u postsocijalističkim nacionalnim narativima žrtve i memorijalizaciji zločina, ${ }^{15}$ Šnajder je tražio da se svi društveni akteri vrate antifašističkoj odgovornosti. Kratko pre praizvedbe ovim rečima je završio jednu od svojih angažovanih kolumni: „Želimo reći sljedeće: u Jasenovcu se nije umiralo, tamo se ubijalo. I za katarzu, koja se ovdje mora pripremiti, daleko je važnija umjetnost od politike, svejedno kakva je. I što prije to shvatimo, tim bolje.“ (Šnajder, 2007/7: 274)

Šnajder koristi materijal 'zakasnelog svedoka jednog doba', kako bi isprovocirao suočavanje sa zanemarenim, zatomljenim i zloupotrebljenim znanjem. Uz pomoć dnevnika logorsko iskustvo postaje čitljivo kao događaj kojim se tragovi prošlosti od pre pola veka vraćaju u sadašnjost. Za korišćeni ,transideološki pogled“ (Šnajder, 2007/9: 122) odabran je labav, nepovezan niz scena sa pojedinim motivima iz Jakovljevićevog dnevnika. Šnajder zna da se sa temom logora na sceni ne može izaći na kraj dokumentarno-realističnim sredstvima. Kao moto teksta odabrao je Adornovu izjavu: „Privid je tako koncentrisan da njegovo raskrinkavanje objektivno poprima karakter halucinacije“ (Šnajder, 2007/9: 125). ${ }^{16}$

\footnotetext{
${ }^{13}$ Autor je devedesetih godina pre svega živeo u Nemačkoj i Francuskoj.

${ }^{14}$ Praizvedba je bila 3. aprila 2004. u Zagrebu (Zagrebačko kazalište mladih).

${ }^{15} \mathrm{O}$ ambivalentnom tretiranju Jasenovca kao mesta sećanja sada postoji priličan materijal; na nemačkom jeziku vidi npr. Höpken, 2006; Mappes-Niediek, 1998; Sundhaussen, 2003; Oschlies, 2004; Radonic, 2010.

16 Kao moto poziva još jednog svedoka. Radi se o poznatom književnom istoričaru i kritičaru Antunu Barcu (1894-1955), koji život zatočenika opisuje kao sličan bunilu u
} 
Početak je zamišljen kao ,rijaliti šou“, kako se saznaje iz pratećeg teksta, kao obilazak logora negde u Srednjoj Evropi uz pomoć stručnog vodiča. Tom „uglednom društvu modernih nomada“ (op.cit.) pridružuju se i ,akteri prošlih događaja“ (op.cit.), koji su fiktivne, ili kao npr. Maks Luburić, komandant koncentracionog logora Jasenovac, istorijske ličnosti. Od svih učesnika ove „ekskurzije“ traži se da se posluže postojećim ,rekvizitima“ nekadašnjih logoraša i da na taj način glume zatočenike logora. Odatle počinje niz od 19 scena, koje pobliže prikazuju posebnu varijantu nekadašnjeg „,balkanskog Aušvica“. U svom tekstu „Princip Auschwitz“ iz 1995. Šnajder piše sledeće:

A između Auschwitza i Jasenovca ima samo jedna razlika, koja nas, slijedimo li skurilnu metaforiku Heinera Müllera, prati do u naše dane; razlika je to između ubilačkog principa kao principa makinalnog, mašinelnog, tojest odnosećega se na mašinu, i ručnog rada, učinka supijanih manuelaca (up. Šnajder, 1999: 83).

U pojedinim scenama nalik fragmentima sećanja, koje podsećaju na ludnicu (ne samo, ali i nacionalne) istorije, nema boga. Peto jevanđelje je jevanđelje žrtava. Kritika u podtekstu odnosi se na vreme posle rata - stvarna Jakovljevićeva sudbina, u drami predstavljena kao predskazanje, objavljuje se već unapred u 16. sceni pod nazivom „Glavnjača“. Jakovljevića, koji je preživeo logor Stara Gradiška, posle 1945. godine su pod izgovorom da je britanski agent uhapsili predstavnici nove vlasti u Jugoslaviji i najverovatnije likvidirali, iako je zvaničan uzrok smrti glasio samoubistvo vešanjem. ${ }^{17}$

\section{ZAKLJUČNE PRIMEDBE}

Nasleđe antifašizma i narativ pamćenja odigrali su bitnu ulogu $u$ jugoslovenskim književnostima, koje su i same, kako je pokazano u ovom tekstu, oblikovale i osmišljavale antifašizam kao mesto sećanja. Ova dinamika se zasnivala na visokom vrednovanju toposa samooslobođenja tokom antifašističkog narodnooslobodilačkog pokreta $\mathrm{u}$ Drugom svetskom ratu, koji je nastavljen „socijalističkom revolucijom“. Antifašizam je dugo vremena bio prilično stabilan narativ. U kulturi sećanja socijalističke države smatrao se pokazateljem političke pripadnosti u smislu identitetskog povezivanja naroda i narodnosti bratstvom i jedinstvom.

kojem pojedinac nije znao da li sve to sanja ili je granica prema ludilu već dosegnuta (up. Šnajder 2007/7: 125).

${ }^{17}$ To se može zaključiti na osnovu dokumenata koji su priloženi tekstu. 
Bez obzira na tendenciju idealizacije i simplifikacije pokreta otpora i oružane borbe od strane autora koji su i sami bili članovi partizanskog pokreta i raspolagali biografskim, odnono iskustvenim sećanjem, u javnost se probijao sve veći broj književnih koncepata koji su razbijali uvrežene narative i mitove. Bez obzira na otpore prihvatanju pojedinih tekstova u javnom diskursu, oni su imali za posledicu znatnu deeskalaciju i pre svega pluralizaciju stavova. U vremenima rastućeg nacionalizma predstavljali su i jednu vrstu opomene i upozorenja.

A danas? Čini se da antifašizam danas više nije prihvaćen, da je njegov sadržaj razvodnjen i da je on sam postao daleko komplikovaniji kao mesto sećanja, jer podseća na zajedničku istoriju pokreta otpora i jugoslovenskog socijalističkog državnog projekta. Ipak, konfiskacija sećanja ili njihova demonizacija niti „simbolična kastracija antifašizma“ (Paković, 2015: 16), pa ni uništavanje spomenika ne mogu umanjiti značaj i vrednost antifašističke borbe i njenog nasleđa. Ali, tretman antifašizma u pojedinim istočnoevropskim društvima nije jednostavan, izjavljuju urednici broja časopisa Beton International Alida Bremer i Saša Ilić, koji su „okrenuti Istoku“ anketirali autorke i autore o aktuelnom značenju pojma antifašizma (up. Bremer-Ilić, 2015: 2).

Na kraju, osim neophodnosti kritičkog samopromišljanja, ponovno kritičko čitanje književnih tekstova i sagledavanje njihovog odnosa prema memorijalnokulturnim procesima može nam pružiti dragocen uvid u pitanja koja kulture sećanja i antifašizam kao mesto sećanja otvaraju.

Angela Richter

\section{ANTI-FASCISM AS A PLACE OF MEMORY: A $21^{\text {ST }}$ CENTURY READING}

\section{Summary}

One of the motives to write this article was the statement that "there is no common remembrance culture" (Kolditz). On the one hand, this necessitates a plurality of memories, but on the other, it bears a risk of revisionism and relativisation of the antifascist struggle and its societal and cultural legacies. That is why I decided to look back at the recent Yugoslav literary past and evoke protagonists, topics and auctorial positions which made antifascism as the place of memory an integral part of the cultural discourse. It should be stressed that the authors whose works I introduced in this article also critically looked at the mythologems of the SFRY. Hence, this kind of analysis shows that the narratives of remembrance, despite the efforts of the ruling ideology to make them homogenous and indisputable, can be subverted and questioned, especially within and by literature which itself deals with narration and narrativization. Special focus on the play Hrvatski Faust (Croatian Faust, 1981) by Slobodan Šnajder is expressive: by establishing a parallelism among the action and the protagonists in the time of the NDH and the following communist period, the author suggests the congruency between the repressive policies of the Ustasha 
but also of the Yugoslav, antifascist establishment. Being a valuable literary document of the resistance to repression in any system, this play also questions the exploitation of the antifascist narrative as the mythologeme which undermines the critique of the authoritarian politics effectuated by the declared antifascist state. Conclusions of this article centre on the need to critically revaluate the past, but also to persist in defending values represented by antifascism as the place of memory and the foundation of the present and future society of humanity and justice.

Keywords: antifascism, place of memory, narratives of remembrance, Yugoslav literatures, Hrvatski Faust

\section{LITERATURA}

Ahbe, Thomas (2007). Der DDR-Antifaschismus. Diskurse und Generationen Kontexte und Identitäten. Ein Rückblick über 60 Jahre. Leipzig: GNN.

Bašić, Natalija (2007). „Wen interessiert heute noch der Zweite Weltkrieg?“. U: Harald Welzer (ed.): Der Krieg der Erinnerung. Holocaust, Kollaboration und Widerstand im europäischen Gedächtnis (150-185). Frankfurt/Main: Fischer Taschenbuch.

Bernik, France-Dolgan, Marjan (1988). Slovenska vojna proza. Ljubljana: Slovenska Matica.

Bienek, Horst (1965). Borges, Bulatovic, Canetti. Drei Gespräche mit Horst Bienek. München: Hanser.

Bobinac, Marijan (2005): „Bernhards Heldenplatz und Šnajders Kroatischer Faust. Zum Phänomen des ,Nestbeschmutzers' ${ }^{6}$ in der österreichischen und kroatischen Literatur". Bernhard-Jahrbuch, 141-148.

Bremer, Alida, Ilić, Saša (10.03.2015). Europa 70 Jahre nach dem Ende des Zweiten Weltkriegs. Beton International. Zeitung für Literatur und Gesellschaft, 2.

Brunnbauer, Ulf (2010). „Umkämpfte Vergangenheiten. Vorwort von Ulf Brunnbauer“. U: Kuljić, Todor: Umkämpfte Vergangenheiten. Die Kultur der Erinnerung im postjugoslawischen Raum. Bonn: Bundeszentrale für politische Bildung. 7-12.

Colombi, Matteo (2014). „Andere Geschichten. Das Nachleben der Partisanen in der slowenischen Kunst und Literatur", U: Gölz, Christine, Kliems, Alfrun (ed.). Spielplätze der Verweigerung. Gegenkulturen im östlichen Europa Wien/Köln/Weimar: Böhlau. 174-201.

Danyel, Jürgen (1995). Die geteilte Vergangenheit - Zum Umgang mit Nationalsozialismus und Widerstand in beiden deutschen Staaten. Berlin: Akademie. 
Heukenkamp, Ursula (ed.) (1990). Unerwünschte Erfahrung. Kriegsliteratur und Zensur in der DDR. Berlin/Weimar: Aufbau.

Höpken, Wolfgang (1996). „Der Zweite Weltkrieg in den jugoslawischen und postjugoslawischen Schulbüchern“. U: Isti (ed.). Öl ins Feuer?/Oil on Fire? Schulbücher, ethnische Stereotypen und Gewalt in Südosteuropa Hannover: Hahnsche Buchhandlung. 159-176.

Höpken, Wolfgang (2006). „Jasenovac - Bleiburg - Kočevski Rog: Erinnerungsorte als Identitätssymbole in (Post-)Jugoslavien“. U: Richter, Angela/Beyer, Barbara (ed.). Geschichte (ge-)brauchen. Literatur und Geschichtskultur im Staatssozialismus, Jugoslavien und Bulgarien Berlin: Frank\&Timme. 401-432.

Jakir, Aleksandar (2012). „Remembering the Partisans, the Second World War and Bleiburg in Croatia“. U: Zimmermann, Tanja (ed.): Balkan Memories. Media Constructions of National and Transnational History Bielefeld: transcript, 187-205.

Jakiša, Miranda (2012). „Der ,tellurische Charakter ${ }^{6}$ des Partisanengenres: Jugoslavi sche Topo-Graphie in Film und Literatur". U: Kilchmann, Esther/Pflitsch, Andreas/Thun-Hohenstein, Franziska (ed.). Topographien pluraler Kulturen. Europa vom Osten gesehen, Berlin: Kulturverlag Kadmos, 207-223.

Jakiša, Miranda-Gilic, Nikica (ed.) (2015). Partisans in Yugoslavia. Literature, Film and Visual Culture. Bielefeld: transcript.

Jambrešic-Kirin, Renata (2006). „Politička sjećanja na Drugi svjetski rat u doba medijske reprodukcije socijalističke kulture“. U: Lada Čale Feldman/Ines Prica (ed.): Devijacije i promašaji: Etnografija domaćg socijalizma Zagreb: Institut za etnologiju i folkloristiku, 149-177.

Karge, Heike (2006). „Offizielle Narration trifft lokale Praktiken. Kriegsgedenken und Denkmalsbau in Jugoslawien“. U: Richter, Angela/Beyer, Barbara (ed.). Geschichte (ge-)brauchen. Literatur und Geschichtskultur im Staatssozialismus: Jugoslavien und Bulgarien, Berlin: Frank\&Timme, 91111.

Karge, Heike (2010): Steinerne Erinnerung - versteinerte Erinnerung? Kriegsgedenken im sozialistischen Jugoslawien. Wiesbaden: Harassowitz. Konstantinović, Zoran (1987). „Von der Diskursivität des Bösen. Šnajders Kroatischer Faust als jugoslawischer Beitrag zum Faust-Satan-Verhältnis“. LiLi 67, 111-115.

Kenneweg, Anne Cornelia (2009). Städte als Erinnerungsräume. Deutungen gesellschaftlicher Umbrüche in der serbischen und bulgarischen Prosa im 
Sozialismus. Berlin: Frank\&Timme.

Kuljić, Todor (2010): Umkämpfte Vergangenheiten. Die Kultur der Erinnerung im postjugoslawischen Raum. Bonn: Bundeszentrale für politische Bildung.

Leo, Annette-Reif-Spirek, Peter (ed.) (1999). Helden, Täter und Verräter. Studien zum DDR-Antifaschismus. Berlin: Metropol-Verlag.

Leo, Annette - Reif-Spirek, Peter (ed.) (2001). Neue Studien zum DDRAntifaschismus. Berlin: Metropol-Verlag.

Leo, Annette (2009). „Antifaschismus“. U: Sabrow, Martin (ed.). Erinnerungsorte der DDR München: C.H. Beck, 28-40.

Leo, Maxim (28./29.3.2015). „Der Junge von Buchenwald“. Berliner Zeitung, 3.

Mappes-Niediek, Norbert (08.05.1998). „Die Schlächter und die Geschlachteten“. Freitag, 20.

Münkler, Herfried (2009). „Antifaschistischer Widerstand, frühbürgerliche Revolution und Befreiungskriege. Die Gründungsmythen der DDR“. U: Isti (ed.). Die Deutschen und ihre Mythen Berlin: Rowohlt, 421-453.

Oschlies, Wolf (2004). „Das kroatische KZ Jasenovac“, URL: http://www.zukunftbraucht-erinnerung.de/das-kroatische-kz-jasenovac/ (22.08.2016).

Peković, Ratko (2009). Paralelna strana istorije. Sporovi o jeziku, naciji, literaturi 1945-1990. Beograd: Albatros plus.

Petzer, Tatjana (1998): „Die ,kalten Tage“ im Werk von Danilo Kiš‘، U: Literaturmagazin 41, 113-120.

Radonić, Liljana (2010). Krieg um die Erinnerung. Kroatische Vergangenheitspolitik zwischen Revisionismus und europäischen Standards. Frankfurt/Main-New York: Campus.

Richter, Angela (1995): „Liberalität ohne Grenzen? Zum Umgang mit Literatur in Jugoslawien 1945-1990“. U: Richter, Ludwig/Olschowsky, Heinrich (ed.). Im Dissens zur Macht. Samizdat und Exilliteratur der Länder Ostmittel- und Südosteuropas Berlin: Akademie-Verlag. 245-256.

Richter, Angela (1999): „Festszenen bei Bulatovic“. U: Leitner, Andreas/Burkhart, Dagmar (Hg.): Prazd'nik'. Von Festen und Feiern in den slavischen Literaturen Frankfurt/Main et al.: Lang, 213-222.

Richter, Angela (2006): „Erzählen und Moral - $\mathrm{Zu}$ einigen Aspekten der Romane Aleksandar Tišmas und ihrer Aufnahme in Deutschland“. U: Schubert, Gabriella (Hg.): Serben und Deutsche. Zweiter Band. Literarische Begegnungen, Jena: Collegium Europaeum Jenense, 259-274. Sabrow, Martin (ed.) (2009). Erinnerungsorte der DDR. München: C.H. Beck. Šnajder, Slobodan (1999): „Princip Auschwitz“. U: Isti (ed.): Kardinalna greška. Opasne veze I, Rijeka: Adamić: Novi list, 79-83. 
Šnajder, Slobodan (2007/7). San o mostu. Kolumne. Zagreb: Prometej (=Izabrana djela. Treće kolo, sv. 7).

Šnajder, Slobodan (2007/9). Faustova oklada. Drame. Zagreb: Prometej (=Izabrana djela. Treće kolo, sv. 9).

Sundhaussen, Holm (2003). „Jasenovac 1941-1945. Diskurse über ein Konzentrationslager als Erinnerungsort“. U: Ueberschär, Gerd R. (ed.), Orte des Grauens. Verbrechen im Zweiten Weltkrieg Darmstadt: Primus Verlag, 49-59.

Sundhaussen, Holm (2004). „Jugoslawien und seine Nachfolgestaaten: Konstruktion, Dekonstruktion und Rekonstruktion von ,Erinnerungen' und Mythen“. U: Flacke, Monika (ed.). Mythen der Nationen: 1945 - Arena der Erinnerungen. Bd. 1., Berlin: Deutsches Historisches Museum, 373-426.

Sundhaussen, Holm (2012). Jugoslawien und seine Nachfolgestaaten 1943-2011: eine ungewöhnliche Geschichte des Gewöhnlichen. Wien et al.: Böhlau.

Sundhaussen, Holm (2013). „Das Projekt Jugoslawien: Von der Wiege bis zum Grab“. U: Tomić, Đorđe et al. (ed.). Mythos Partizan. (Dis-)Kontinuitäten der jugoslawischen Linken: Geschichte, Erinnerungen und Perspektiven Münster: Unrast, 28-45.

Tribina „Između povijesti i pamćenja“, URL: http://www.art-kino.org/hr/film/ antifasizam-izmedju-povijesti-i-pamcenja (15.08.2015).

Ugrešic, Dubravka (1994). Die Kultur der Lüge. Frankfurt/Main: Suhrkamp.

Végel, László (2008). „Dämonen der postsozialistischen Demokratie in Serbien“. Europäische Rundschau: Vierteljahresschrift für Politik, Wirtschaft und Zeitgeschichte, 36, 1, 27-34.

Vidulić, Svjetlan Lacko (2011): „Faust, ein kroatischer Mann. NS-Faustik und Erin- nerungspolitik bei Slobodan Šnajder“. U: Kakanien revisited, URL: http://www. kakanien.ac.at/beitr/fallstudie/SVidulic4pdf (14.08.2011).

Vladiv-Glover, Slobodanka (1994). „Hourglass as the Scene of Writing“. Review of Contemporary Fiction 14, 1, 69-85 